\title{
THE 16 MACAQUES OF THE UNIVERSITY OF MODENA HAVE BEEN ADOPTED BY LAV, AN IMPORTANT CASE OF REINTEGRATION OF ANIMALS USED FOR ANIMAL TESTING
}

Carla Campanaro ${ }^{1}$

The 16 macaques that were owned by the University of Modena have been adopted by LAV, one of the most important animal rights NGOs in Italy (www.lav.it).

In compliance with the agreement that provided the end of testing on nonhuman primates, asked for a long time by LAV to the authority of the University of Modena, the University and the city's municipality have entrusted the animals to LAV, which has been chosen by the technical Commission and the Association of Veterinarians, after having presented the best proposal for the care and welfare of the macaques.

This activity is regulated by article 19 of the Italian Decree about protection of animals used in animal testing (D.lgs 26/2014 which adopts European Directive 2010/63) which provides cases of liberation and reintegration of these kinds of animals, when the animal tests are stopped with the objective of giving a new life to these animals. The Decree provides that the veterinarian of the Centre has to decide if it is possible to free the animals and the best destination for them.

LAV, an NGO recognized both by the Ministry of Health and the Ministry of Environment, relies on the financial support of its members and supporters to meet the animals' everyday needs and requirements for the rest of their lives, together with the Recovery Centre for Wild and Exotic animals of Semproniano in the Maremma region. The Recovery Centre offers two new facilities, especially designed to accommodate the macaques, an in-house veterinarian and two primatologists, as well as everything the animals may need to regain their socializing skills, the ability to feed themselves with fruit and vegetables, warm themselves and play in natural sunlight. During the first few weeks, it is paramount that the animals adapt gradually to their new surroundings, so that they feel safe ${ }^{2}$.

\footnotetext{
${ }^{1}$ Attorney at law in Rome and Head of LAV Legal Office.

${ }^{2}$ For further information, see:

http://corrieredibologna.corriere.it/bologna/notizie/cronaca/2016/26-luglio-2016/niente-piumacachi-universita-sedici-animali-cambiano-casa-240733049775.shtml http://www.lastampa.it/2015/04/15/societa/lazampa/animali/salvi-i-macachi-delluniversit-dimodena-e-reggio-G31xmaDINVjfMzcwoNfngK/pagina.html
} 